\title{
The Library Department Head in the Context of Matrix Management and Reengineering
}

\section{Alex Bloss and Don Lanier}

\begin{abstract}
Academic libraries are experiencing significant organizational changes that are having an impact on the library department head. The library department head's job has undergone a dramatic shift from what was, until relatively recently, the typical middle manager's line command position in the bureaucratic hierarchy. Literature analyzing these changes has been reviewed and is discussed in the context of a specific effort to reengineer library technical service operations.
\end{abstract}

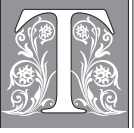

he phenomenal changes seen in library operations in the past five years have led to a review of traditional library organization and management patterns in many libraries. All kinds of organizations are trying to help employees understand and keep up with organizational change. Institutes and workshops promise to help employees assess the current culture of the organization, determine needed changes, and then to prepare for the changing environment. The importance of organizational culture has increased in our society, characterized by its global perspective and technological bent.

Joseph A. Boisse, among others, has delineated some of the factors that make the status quo an impossible option. ${ }^{1}$ As a result, different management and organizational styles are cropping up all over the library landscape. More than ever before, the library department head is caught in the middle. On the other hand, considering the possibilities inherent in a dynamic management and institutional environment, it may be more accurate to suggest that the department head is in the middle of initiatives that will redefine librarianship in the twenty-first century.

The role of the department head has not received a great deal of attention in the library literature. Ann F. Lucas has summarized the key responsibilities of academic department heads. ${ }^{2}$ She describes nine specific duties, at least four of which deal with motivating the faculty. Several of the duties described are applicable to any hierarchical organization-e.g., leading, motivating, evaluating, and managing conflict. Lucas focuses on leadership and faculty development,

Alex Bloss is Head of Acquisitions and Assistant Professor at the University of Illinois at Chicago; e-mail: Alex.Bloss@uic.edu. Don Lanier is Health Sciences Librarian (Rockford) and Associate Professor at the University of Illinois at Chicago; e-mail: dlanier@uic.edu. 
as opposed to department management. Although the authors have chosen not to discuss the issue of librarians as faculty in this paper, it is clear that faculty appointments for librarians have the potential to greatly influence the nature of the department head's job. Larry Oberg and Fred Heath have articulated the logic and value of faculty appointments for librarians. ${ }^{3}$ Although Lucas's observations are analogous to the library department head in many ways, it probably is true that personnel and operations management is the primary focus for department heads in libraries, as opposed to faculty development per se. In libraries, the development of faculty most often is considered a key responsibility of the library director.

Tom H. Ray and Pat Hawthorne compiled a SPEC Kit on librarian job descriptions for the Association of Research Libraries (ARL). ${ }^{4}$ One conclusion from the survey of ARL institutions was that there is little or no standardization about how libraries describe jobs. In any case, only a few of the documents compiled are concerned with department head positions and are able to provide a snapshot of library department head responsibilities in the libraries surveyed. Among the responsibilities most commonly mentioned in the department head job descriptions are planning and policy making. Stefanie A. Wittenbach, Sever Michael Bordeianu, and Kristine Wycisk surveyed the management preparation and training of department heads in ARL libraries, and found that experience and training carried equal weight in determining whether a person became a department head. ${ }^{5}$

The nature of the department head responsibilities identified in most of these studies would indicate that any kind of organizational change will have a significant impact on specific department head duties and the resulting organizational relationships. Perhaps the most likely results will be made clearer by contrasting the traditional library department head with the department head's job after the institution has undergone any one of several management style changes.

\section{The Traditional Department Head}

Literature such as that reviewed above and the authors' personal experiences in several libraries produce a picture of library department head responsibilities that might be referred to as the "traditional view." Consider the following description which has been synthesized from internal documents from a number of universities:

A library department head is the chief administrative officer for a department and is accountable directly to the director or an assistant director for all aspects of the operation and development of that department. The department head is the spokesperson for the department in all official transactions with department members, as well as with other units of the university, and is responsible for the proper functioning of the department as an instructional, research, and public service unit. The department head is responsible, in consultation with appropriate department staff and library administration, for developing and administering operating policies and practices which are effective and consistent with library and university provisions; for maintaining solid and ethical working relationships with vendors and service providers used by the library; for making budget, curricular, and personnel recommendations, and for managing all the resources assigned to the department; for defining the department's scope, mission, 
and objectives within institutional guidelines; and within the resources available, for assuring and, whenever possible, for improving the department's capacity to carry out its mission and accomplish its objectives with distinction.

In addition, traditional department head responsibilities have included budgeting and fiscal management of departmental resources, managing day-to-day administrative responsibilities, scheduling and providing for job assignments, and supervising and evaluating staff assigned to the department.

In the traditional setting, the quality of departmental leadership can be measured by such factors as:

- strength of the staff attracted and retained;

- quality of the department's programs/services;

- enthusiasm of faculty and students for the department's programs and services;

- quality of representation concerning the mission and needs of the department which is provided to units and agencies outside the department;

- level and degree of effective cooperation provided to units and agencies outside the department;

- handling of departmental affairs so as to maximize the time and effort staff can devote to their duties;

- maintenance of high professional and ethical standards on the part of the department in carrying out appropriate contracts, agreements, and working relationships with providers of services to the library;

- ability to get the department to respond with dispatch in facilitating change, when necessary, without violating the rights or ignoring the responsibilities of faculty, staff, or students.
Perhaps more so than in other departments, library department heads seldom have exercised the above responsibilities fully. In particular, they have held delegated responsibility only in a few areas and have had very little authority in the areas of staff supervision and evaluation and in routine operational budget control. This is especially true in recent decades, where budgets are micromanaged and personnel administration is driven by concerns about grievances, litigation, and diversity. Centralized governance may be necessary in some cases but should not unnecessarily deprive the department head of discretionary powers. Any arrangement that does so results in a figurehead position, not a true department head. Of course, the department head, like all other institution administrators, must cooperate with institutional guidelines on personnel and budget.

\section{The Reengineered Department Head}

The above traditional view of department head responsibilities may be contrasted with some current attempts to incorporate team management concepts and matrix organization patterns into the operation of libraries. Indeed, the more flattened organization charts that appear to be evolving may mean that both the assistant director and department head positions in libraries will go the way of the dinosaur. The role of the department head has changed significantly in recent years as libraries have moved to more open management styles. Job ads have appeared for "team leaders," making it clear that the traditional department head responsibilities will have to be accomplished with a different approach. Administrators are reassessing the structure of academic libraries and have been experimenting with new organizational and management styles in response to external and internal pressures. One 
assumes that responses are meant to maintain and improve the library's mission and service goals, and not simply to incorporate current management trends into the operation of the library. Sarah M. Pritchard makes an interesting observation about the purpose of reengineering and benchmarking:

Are we just throwing around different trendy terms from year to year? On the contrary, we have been skirting this key issue for a long time. Librarians must work with faculty, administrators, and other campus and education groups to try to decide what are the institutional outcomes of good library and information service. We are a long way from being able to quantify this, but some of the ideas that have emerged in the literature include studying links between library inputs/outputs and the following educational outcomes:

- Faculty research productivity (measured by grants, publications, and awards).

- Student learning and success (as reflected by tests, advanced degrees, and job placements).

- National resource development (contribution to the national education enterprise as measured by materials cataloged and preserved, support of resource sharing, or networks and databases established) ${ }^{6}$

Joanne R. Euster has described an early example of matrix organization for a specific library division. She observes that matrix is a management structure that accommodates both diversification of responsibilities and the need for control. ${ }^{7}$ Helen H. Britton has presented a case study of the transition from hierarchical organization to matrix at California State-
Long Beach. ${ }^{8}$ Susan A. Hawk and Jeanne Goshorn have given an account of matrix management at the National Library of Medicine, including the reasons matrix management has been utilized and some of its unique aspects. ${ }^{9}$ One of their conclusions is that matrix managers must rely more on personalities, perceptions, and leadership abilities than do managers who have traditional line authority. Interestingly, Richard E. Anderson suggests that matrix structures that were tried, but not permanently adopted, a decade or two ago are now popular under the guise of "empowered teams."10 This is not to suggest that current matrix applications are bogus and doomed to failure. The convergence of technological, budget, and other factors discussed earlier may mean the time is right for such management methods. Peggy Johnson has presented a well-documented case for matrix management as an "organizational alternative" in libraries. ${ }^{11}$ Richard T. Sweeney refers to this as the "post-hierarchical library."12

Total quality management (TQM) and reengineering have been the most recent tools in a long string of methods to evaluate organizational models and effect changes. These changes often result in downsizing and flattened organizations, but they also result in an empowerment of support staff at much lower levels than previously known. As a result of these reevaluations, which in fact reflect similar efforts in the for-profit sector, we are seeing the growth of team management, matrix organization, and organizational simplification. Decisions previously taken by upper management in many institutions now are being proposed, instituted, and evaluated by those most closely affected by the change. As these changes are being implemented, the role of middle managers in a library, that is, the department heads, is being challenged and redefined as well. 


\section{The UIC Experience}

The library of the University of Illinois at Chicago (UIC) is presently reengineering its technical services operations. Though this paper is not meant to be a description of the reengineering project, some of the salient features of UIC's particular evolution are as follows. In 1993, as an early step in the library's transformation, two associate university librarian positions were eliminated, thus flattening the organization and vesting more authority with the department heads. In 1994, library faculty and staff set a vision of what technical services (acquisitions and cataloging) in the library should be in the year 2000 . This vision anticipated continuing advances in technology, such as electronic publishing and EDI, anticipated fiscal restraints, and new products offered by library vendors. It should be noted that preparing for such changes was the underlying reason for embarking on a sizeable reengineering effort. Reengineering was not seen as a remedy for processing, staffing, or other kinds of organizational problems, nor as a means of downsizing staff levels. Rather, the purpose was much the same as that given by Thomas W. Shaughnessy in his account of a restructuring effort at Minnesota, when he said: "The most important reason for restructuring, however, is also the most abstract, namely, that libraries must be organized to deal with the extraordinary changes that are occurring in their environment." 13

A reengineering structure was developed at the UIC library, consisting of a steering committee and two teams. The teams were composed primarily of support staff from the technical services departments of UIC's main library and its health sciences library. The teams were guided by librarians, called champions, whose responsibilities were outside the technical services departments and who represented the teams to the steering committee. The roles of the teams were to evaluate present technical service processes and to make recommendations for change. One team was constituted to study processes before library materials were received; the other studied processes after the receipt of materials.

The roles of the steering committee were primarily to monitor and guide the process, provide support for the teams, and clear barriers from the proposals emanating from the teams. The steering committee consisted of senior library management, including the head of library systems, the heads of two technical services departments, the principal bibliographer, and a branch/regional site library representative. The champions of the two teams, who happened to be circulation department heads from both the main library and the health sciences library, also were on the steering committee.

As the reengineering process evolved, it became obvious that proposals from the teams would cross the traditional cataloging and acquisitions department lines, that other library departments and offices would become deeply involved, and that a lot of responsibility and power was vested in the reengineering teams. Keeping in mind that the role of the teams was to propose changes and that the role of the steering committee was to clear barriers to their proposals, the position of the department heads whose departments were being studied was an awkward one at best. It quickly became obvious that these roles limited the department heads' previous autonomy to initiate and manage change in their departments and to respond to outside forces as necessary.

Because part of the reengineering process entailed work flow evaluation and the monitoring of particular processes, the department heads were constrained from changing these processes; in fact, 
this meant a stagnation of the natural changes in a department as benchmarks were being set, process time measured, etc. One response to this dilemma was development of a "Statement of Responsibilities of Unit Managers," which reads as follows:

The Reengineering Steering Committee recognizes that managerial changes and the reengineering process may be in conflict on occasion. In order to assure effective change, unit heads have the responsibility and the right to meet with the reengineering teams as necessary to propose changes to processes and to seek the teams' input and advice on these changes. In the same manner, reengineering teams are expected to involve the unit manager at an appropriate time in their deliberations in order to get that person's input to changes that they may propose. In both instances the team and the unit manager will agree on whether the proposed change needs to be part of the reengineering process, and what sort of tracking and evaluation will be necessary if the change is implemented.

In developing this statement, the steering committee recognized that change was a necessary and problematic fact of life and that planned and managed change should be embraced. It further recognized that department heads were responsible for the day-to-day operations of their units and, within that context, had the prerogative to make changes as necessary. In addition, it recognized that reengineering teams were charged to study processes and make recommendations to improve them within the context of the reengineering effort.
In effect, though, this policy also signaled a change in how process development occurred and thrust the department head into a new role. Many excellent proposals have come from the reengineering teams. Such proposals, coming from the staff closest to the processes, required little buy-in from them. In some instances, it was the department head who was required to accept changes to policy that were initiated by the staff. Responsibilities among sections of departments began to shift, and lines between departments began to blur. Traditional domains were being called into question. Two examples at UIC demonstrate the effect of these changes in process development.

First, at present, preorder work is done in the Catalog Department (in itself a relatively nontraditional approach), and order-record creation and vendor assignment is done in the Acquisitions Department. The reengineering team has proposed that preorder verification, bibliographic record creation, and orderrecord creation on NOTIS be combined into one process and done within one department. The departmental location of this process has yet to be determined. The other part of the proposal is even more unsettling in that it recommends that collections development staff assign vendors and do some preorder work, such as price and perhaps availability determination. Deposit accounts will be set up with selected vendors to lessen the processing of vouchers and invoices. The role of the Acquisitions Department surely will be changed as a result. Where the responsibilities of the Acquisitions Department head would increase is in vendor monitoring and evaluation, management of a number of deposit accounts, and a closer relationship with the collections development staff who will assign vendors.

The second major proposal is to move toward shelf-ready receipt of library ma- 
terials. Full bibliographic records are to be delivered along with books that are fully processed and ready to shelve. A receiving unit will be set up in close proximity to the library's loading dock. The receiving unit will likely accept the materials, perform some quality control on the processed items, change order-record status to received status, and send fully processed materials directly to shelves, whereas items with incomplete catalog records will be referred to cataloging. Full bibliographic records will be added to the database, as needed. Such a proposal would affect cataloging, acquisitions, shelf preparations, and library systems staff, and would represent a major change in work flows and responsibilities to each.

Though these proposals have been made and accepted in principle by the steering committee, the next step is an implementation phase where the proposals will be tested using selected vendors or types of library material. It becomes apparent, however, that the role of the department head in process management has become diminished as the support staff take on more responsibility. Over the short run, as the processes change, department heads will be responsible not only for ensuring that the process change is managed appropriately but also that the relationships among the various departments and sections evolve smoothly at the same time that their own responsibilities are diminished.

Where the responsibility has shifted, and what the authors see as a future model for the role of a department head, is increased responsibility for:

- guiding staff and serving as a resource to them as they take on added responsibility for the direction their work is taking;

- coordinating activities between departments, especially as traditional roles begin to blur or merge;
- monitoring and recommending staffing levels and job descriptions to the library director;

- clearing barriers so that new proposals can be implemented;

- providing a heads-up profile in the profession to monitor changes in the environment and to pass along ideas learned from colleagues;

- negotiating contracts and licenses, and monitoring vendor performance (especially when vendor products and services also cross boundaries between departments).

Conversely, some of the roles that department heads traditionally have been expected to perform now are being delegated to support staff, including:

- initiating new programs, routines, or procedures;

- establishing benchmarks for processes;

- effecting close collaboration with support staff in other departments.

For example, following is a group of activities that previously were left largely in the hands of department heads but now are included in the duties of frontline employees: developing procedures for all routine (including professional) tasks; gathering time/task data; reporting regularly (either in writing or orally) specific status on work processed, nonroutine processing, trial procedures in process, projected activities, progress toward achievement of goals, completed projects, and problems requiring action before they become crises; providing input to decision making without having to be asked; seeking out alternative ideas and approaches to library operations (including the expanded use of technology).

Table 1 depicts the allocation of time for the traditional library department head compared with the allocation of time postreengineering. (To be sure, time allocation to various functions is related 


\begin{tabular}{|lcc|}
\hline \multicolumn{3}{|c|}{ TABLE 1 } \\
Allocation of Time for Library & Department Head \\
\hline \hline Responsibility & $\begin{array}{c}\text { Traditional } \\
\text { \% of Time }\end{array}$ & $\begin{array}{c}\text { Post-reengineering } \\
\text { \% of Time }\end{array}$ \\
\hline Human Resources Administration & 15 & 10 \\
Research and Scholarship & 10 & 10 \\
Liaison with Other Library Units & 5 & 10 \\
Liaison With Campus Units & 5 & 5 \\
Program/Services Planning & 20 & 15 \\
Professional Committees & 10 & 10 \\
Budgeting, Data Gathering, Reporting & 10 & 15 \\
Professional Development and Travel & 5 & 5 \\
Correspondence, E-mail, etc. & 15 & 10 \\
Vendor Contact & 5 & 10 \\
\hline
\end{tabular}

directly to the type of department one heads, and differs in main library and site library contexts.) The allocation is based on observations made within departments at UIC, and may not be reflective of environments in other institutions. The "traditional" percentage of time is derived from the experience of the authors, who are both department heads. The postreengineering percentage of time represents anticipated changes in responsibilities of the two technical services department heads whose departments are being reengineered. The shift in percentages reflects the move to lower-level staff of planning and monitoring responsibilities, and the increase in coordination and contact with other departments and vendors that cross traditional lines.

\section{What Next?}

Maxine Brodie and Neil McLean have described the organizational impact of adopting a process framework. ${ }^{14}$ The UIC experience confirms at least some of their observations. They concluded that, "Our ability to achieve organizational changes of this kind will be a key to redesigning the resource delivery process." The role of the unit manager is changing as reengineering begins to take effect. Reengineer- ing teams have identified processes, are setting benchmarks, and are mapping these processes as a means of fixing in time the activities they are studying. At the same time, unit managers are responsible for maintaining a smooth flow of work and, on occasion, must make changes in response to staffing needs, problems, or external developments that may arise. The roles of these two forces are thus not always in harmony when a unit must respond to change in a way that causes extra work for the reengineering team, or a reengineering team proposes changes that will necessitate action on the part of the unit and its managers.

The question may be asked, Is it possible for hierarchical and team management to continue to coexist? Assuming that flatter organizations and team management really provide their espoused benefits, there may be no further need for much of the traditional administrative team, including department heads. Such hierarchical designations and their corresponding job descriptions may only be sources of conflict. Bob Donath says that the functional hierarchy dies hard because it is the kind of tidy management structure revered since the beginning of the Industrial Revolution. ${ }^{15}$ However, he 
goes on to say that the flat organization is replacing the hierarchy because it is flexible and innovative and because highly motivated problem solvers using instant communication work with networks, project teams, and task forces to carry the day, compared to organizations encumbered with vertical decision making and redundant middle managers.

Howard H. Stevenson and Mihnea C. Moldoveanu have said that our virtual organizations and newer management practices are destroying predictability, which is so important in maintaining staff morale, loyalty, and stability. ${ }^{16}$ According to them, reengineering, continuous improvement, matrix management, and "rightsizing" ignore this basic human need. Another criticism of flattening the organization and adopting a process framework is that the key traditional management function of control receives less attention from department heads. Clifford H. Haka compares the flatter organization patterns with the Internet:

I would argue that the Internet is a perfect example of a virtually flat organization. And as one might expect, creativity has flourished beyond anyone's wildest dream. There are already more "wonders" on the Internet than one could ever hope to explore. On the other hand, the organization of resources on the Internet is an absolute mess. It is chaos. There is literally no control. This outcome is not a fluke. It is the natural and predictable result of the organizational design that is being employed. ${ }^{17}$

Achieving a balance in organizational design that will fully utilize both the empowered frontline workers and the department heads with reengineered responsibilities is a big challenge. Anecdotal evidence suggests that both groups may find adapting difficult. Department heads, in particular, may have trouble if they have seen their job as primarily managerial rather than programmatic. An account of one manager may make the point clearer:

Former faculty librarian department managers were expected to move from day-to-day management of their paraprofessionals and resource processing and circulation to strictly collection development, instruction, and reference roles, using a liaison model. This created unbelievable stress and tension-the library faculty simply were not ready for this major paradigm shift. ${ }^{18}$

The experience of the authors, in both flatter organizations such as UIC, as well as in matrix organizations elsewhere, has shown that organizations that utilize team responsibility for getting things done require a high tolerance for ambiguity and change. These qualities are necessary at all levels of staff, not just among department heads. However, even tolerance will not be sufficient when it comes to dealing with continuous change. The department head must embrace change enthusiastically and pass this enthusiasm on to his or her staff. This will be the real measure of the department head's leadership.

\section{Postscript}

The UIC reengineering teams (and particularly the Reengineering Steering Committee) are indebted to many individuals and libraries who have shared their experiences. And UIC staff are committed to reciprocating wherever possible. To some extent, the references below document part of this indebtedness and willingness to share experiences. In addition, the authors direct the readers' attention to UIC's Web reengineering documents and to those of Stanford University Libraries, which were particularly helpful. At UIC, contact: http://www.uic.edu/depts/lib/ reeng/reeng.html; at Stanford, contact: http://www-sul.stanford.edu/depts/diroff/ts/redesign/redesign.html. 


\section{Notes}

1. Joseph A. Boisse, "Adjusting the Horizontal Hold: Flattening the Organization," Library Administration and Management 10, no. 2 (summer 1996): 77-81.

2. Ann F. Lucas, Strengthening Departmental Leadership: A Team-building Guide for Chairs in Colleges and Universities (San Francisco: Jossey-Bass, 1994).

3.Larry Oberg, posting of 10/3/93 to Library Administration and Management listserv (Libadmin); Joyce K. Thornton, "Transition: An Interview with Fred Heath," Library Administration and Management 10, no. 2 (summer 1996): 69-73.

4. Tom H. Ray and Pat Hawthorne, Librarian Job Descriptions in ARL Libraries, SPEC Kit no. 194 (Washington, D.C.: ARL, 1993).

5. Stefanie A. Wittenbach, Sever Michael Bordeianu, and Kristine Wycisk, "Management Preparation and Training of Department Heads in ARL Libraries," CERL 53 (July 1992): 319-30.

6. Sarah M. Pritchard, "Library Benchmarking: Old Wine in New Bottles?" Journal of Academic Librarianship 21, no. 6 (Nov. 1995): 491-95.

7. Joanne R. Euster, "A Matrix Model of Organization for a University Library Public Services Division," in Academic Libraries: Myths and Realities, Proceedings of the 3rd National Conference of the Association of College and Research Libraries, Seattle, 1984 (Chicago: ACRL, 1984).

8.Helen H. Britton, "Interactions: A Library Faculty Matrix Organization and Public Policy and Administration Program," Reference Librarian, no. 20 (1987): 187-204.

9. Susan A. Hawk and Jeanne Goshorn, "Matrix Management as a Framework for Partnerships," Medical Reference Services Quarterly 7, no. 1 (1988): 31-39.

10. Richard E. Anderson, "Matrix Redux," Business Horizons 37, no. 6 (Nov.-Dec. 1994): 6-10.

11. Peggy Johnson, "Matrix Management: An Organizational Alternative for Libraries," Journal of Academic Librarianship 16, no. 4 (Sept. 1990): 222-29.

12. Richard T. Sweeney, "Leadership in the Post-hierarchical Library," Library Trends 43, no. 1 (summer 1994): 62-94.

13. Thomas W. Shaughnessy, "Lessons from Restructuring the Library," Journal of Academic Librarianship 22, no. 4 (July 1996): 251-56.

14. Maxine Brodie and Neil McLean, "Process Reengineering in Academic Libraries: Shifting to Client-centered Resource Provision," Cause/Effect 18, no. 2 (summer 1995): 40-46.

15. Bob Donath, "Going Flat Out for Flat Organizations Isn't Easy," Marketing News 26 (Dec. 1992): 7-8.

16. Howard H. Stevenson and Mihnea C. Moldoveanu, "The Power of Predictability," Harvard Business Review 73, no. 4 (July-Aug. 1994): 140-43.

17. Clifford H. Haka, "Organizational Design: Is There an Answer?" Library Administration \& Management 10, no. 2 (spring 1996): 74-76.

18. E-mail posting to the Medlib-L listserv (1996?). 